\title{
Restraining free-riders: The effects of actor types and decision rules in the public goods game
}

\section{Jan Sauermann}

University of Cologne, Germany

\section{Ulrich Glassmann}

University of Konstanz, Germany

\begin{abstract}
Many experiments comparing individual and group behavior find that groups behave more egoistically than individuals. However, most of these studies do not control for the influence of within-group decision-making rules that might have an important impact on group behavior. In this article, we report findings from laboratory experiments comparing individual and group behavior in a public goods game. We find that rather than cooperation levels differing between individuals and groups per se, the intragroup decision-making rule has an influence on the cooperativeness of groups. Groups decide either by majority or unanimity rule. While groups deciding by majority rule reach roughly the same level of cooperation as individuals, groups deciding by unanimity rule contribute significantly lower amounts to the public good.
\end{abstract}

\section{Keywords}

Cooperation, decision-making rule, group behavior, laboratory experiment, social dilemma

\section{Corresponding author:}

Jan Sauermann, Cologne Center for Comparative Politics, University of Cologne, P.O. Box 4I I 020, 50870 Cologne, Germany. Email: jan.sauermann@uni-koeln.de 


\section{Introduction}

A long line of experimental research has identified a bunch of factors influencing the level of cooperation in social dilemmas (see Coleman and Ostrom, 2011; Ledyard, 1995). However, most laboratory experiments study interactions of individual decision makers and only a few (discussed in section "Theoretical assumptions about the cooperativeness of individuals and groups") take collective actors into account. Yet, in many real-world social dilemma settings, the relevant actors are groups such as cabinets, political parties, parliamentary committees, interest groups, boards of directors, works councils, or families.

Most collective actors are not homogenous but differ in many aspects. Certainly, the way of intragroup decision making is one of the most likely factors to affect the behavior of groups. Acting as a group requires a decision-making procedure among individual group members. It does not matter whether this procedure is written down explicitly or, instead, rests on the compliance with informal norms, yet group action is not possible without a decision-making rule in place. However, the experimental literature lacks an examination of the effects of different formal intragroup decisionmaking rules in intergroup social dilemma settings. In this article, we challenge the assumption that group and individual behavior differ per se, irrespective of such decision-making rules. Therefore, in order to examine how cooperation is influenced by formal intragroup decision-making rules, we design a laboratory experiment which aims at answering two questions. First, we ask whether group actors behave differently from individual actors when both of these types of actors approach a comparable social dilemma setting. Second, we look at the decision-making rule which is applied in the intragroup decision process to ask what impact it has. Thus, our experiment consists of three treatments: we study individual actors, groups deciding by majority rule, and groups deciding by unanimity rule.

Our theoretical argument assumes an interaction of the institutional incentive structure of the intragroup decision-making mechanism and psychological traits. Research in personality psychology has revealed a negative correlation between stubbornness und the cooperativeness of individuals (Goldberg, 1990, 1992). Under unanimity rule, this psychological trait comes into effect because the decision rule assigns veto power to all group members. As egoistic group members are more stubborn than more cooperative group members, decision making under unanimity rule is biased toward lower contributions. Under majority rule, the greater stubbornness of more egoistic group members does not play a role because they can be overruled. Instead, the median preference in a group is the expected outcome. Hence, majority rule inheres a dynamic, empowering moderate group 
members and thus leads to cooperation levels which are similar to cooperation levels among individual actors. Our results support our theoretical claim. While we find no significant differences between contributions to a public good of individual actors and collective actors deciding by majority rule, cooperation rates among groups deciding by unanimity rule are significantly lower.

The rest of this article is organized as follows: in the following section, we give a brief overview of related literature from social psychology and economics on group behavior and lay out our theoretical argument. Section "Experimental design and procedure" introduces our experimental design. In section "Experimental results," we present our results, and the final section concludes.

\section{Theoretical assumptions about the cooperativeness of individuals and groups}

Recent years have witnessed an increasing interest of experimental economists in team decision making. The experimental findings show that group behavior differs from individual behavior in several respects. For instance, groups were found to be more polarized in risk evaluations (e.g. Eliaz et al., 2006). Most important for our study is evidence showing that groups behave more competitively and tend to act more selfishly than individuals. Thus, conflicts among groups tend to be more intense than conflicts among individuals (Abbink et al., 2010; Bornstein, 2003; Bornstein and Ben-Yossef, 1994). Likewise, collective actors send less and return less than individuals in the trust game (Cox, 2002; Kugler et al., 2007), offer smaller amounts as proposers in the ultimatum game (Bornstein and Yaniv, 1998), and exit the centipede game earlier than single players (Bornstein et al., 2004). However, groups do not act more egoistically in all instances. Cason and Mui (1997), for instance, find that group decision making in the dictator game tends to be dominated by the more other-regarding group member, and Bosman et al. (2006) find no behavioral differences between groups and individuals in the power-to-take game. Hence, the question arises which variables dampen or amplify the development of group-egoism and why.

In most papers cited above, members of the same group interact face-toface, deciding without a clearly predetermined decision rule. Consequently, little is known about the effects of formal constraints, especially intragroup decision-making rules, on group behavior. However, there are some important exceptions. For instance, Luhan et al. (2009) use a within-subjects design, where subjects have to make decisions as individuals and as group members in the dictator game. Interacting via a computer network, group members have to reach a unanimous decision. In contrast to Cason and Mui 
(1997), Luhan et al. (2009) find that groups transfer smaller amounts than individuals. Furthermore, they show that the most selfish group member has the greatest impact on the amount offered by a group. ${ }^{1}$ Kocher and Sutter (2007) analyze the gift-exchange game and vary the possibility to communicate during intragroup decision making. In one treatment in which groups interact anonymously via a computer network, groups have to reach a unanimous decision. In this treatment, groups transfer less and choose lower effort levels than individuals. However, in another treatment with face-toface within-group interactions, transfer and effort levels of groups are higher compared to the treatment with individual actors. To sum up, both studies suggest that the requirement to reach a unanimous group decision in an anonymous setting promotes group-egoism.

Experimental results by Gillet et al. (2009), however, challenge this explanation. Gillet et al. compare individual and group behavior in an intertemporal common pool resource game (see Ostrom, 1999). Moreover, they also implement two different group treatments in which groups either decide by majority rule or unanimity rule. The results show that the intragroup decision-making rules matter. Confronted with a nonstrategic intertemporal choice problem without competition between players, groups make qualitative superior decisions irrespective of the intragroup decision-making rule. ${ }^{2}$ However, in a strategic setting with other players, groups deciding by majority rule act more competitively and deplete the common resource more rapidly than individuals, whereas groups deciding by unanimity rule become more competitive than individuals only with repetition of the game. Gillet et al. (2009) conclude that majority rule promotes the development of group-egoism, while the effect is much weaker under unanimity rule and only develops in the course of play.

Overall, the experimental economics literature suggests that behavioral differences between individual and collective actors are influenced by a number of variables, among them the formal institutional rule under which intragroup decisions are made. However, the specific effects of different formal intragroup decision-making rules and possible interactions with other factors are still largely unknown.

The social psychological literature offers other important theoretical insights and empirical evidence on behavioral differences between individuals and groups. For instance, experiments on the prisoners' dilemma have shown that intergroup interactions are more competitive and less cooperative than interindividual interactions (Schopler and Insko, 1992; Wildschut and Insko, 2007). This greater competitiveness of groups is termed "discontinuity effect." The social psychological literature cites three underlying causal mechanisms for this effect, two of them explaining how being member of a group promotes greater greed in intergroup interactions compared 
to interindividual interactions and the third factor explaining the occurrence of group-egoism by fear (Wildschut et al., 2003). Group membership promotes greed for two reasons. First, it offers ways to legitimate more egoistic behavior because it reduces the identifiability of individual responsibility for selfish actions. Second, group members provide each other with social support to pursue their shared self-interest against other actors. Thus, group membership alters informal constraints governing collective decision making. Groups act more greedily than individuals because being part of a group reduces the costs of violating norms promoting cooperative behavior. According to the schema-based distrust or fear explanation of the discontinuity effect, actors reduce their willingness to cooperate in interactions with a group because they anticipate the greater competitiveness of groups and, therefore, respond by acting more competitively themselves.

The social psychological literature portrays the discontinuity effect as a generic difference between the behavior of individuals and groups and, accordingly, disregards possible influences of different intragroup decisionmaking rules. Nevertheless, decision-making rules such as majority and unanimity rule can be incorporated in the given theoretical argument. While it is not clear how majority and unanimity rule influence social support and schema-based distrust, one could argue that the identifiability of individual responsibility for selfish actions is higher under unanimity rule than under majority rule. This is due to the fact that if a group decides by unanimity rule, all group members have to back a group decision. Thus, all group members are responsible for the final decision. Under majority rule, however, single group members can be overruled. This dilutes the ascription of individual responsibility for a group decision under majority rule, because it is not clear whether an individual subject actually voted in favor of the final outcome or against it. According to this reasoning, the identifiability of individual responsibility is highest in interindividual interactions and lowest in group interactions where groups decide by majority rule, with group interactions under unanimity rule in-between. The common social psychological view thus predicts generally higher cooperation rates in interindividual social dilemmas compared to social dilemmas with collective actors. Among intergroup interactions, it can be expected to find more cooperation when groups decide by unanimity rule compared to groups deciding by majority rule.

\section{The interaction of institutional mechanics and personality traits}

We argue that a different mechanism causes behavioral differences between collective actors deciding under different decision-making rules. The review of the economic literature highlights the importance of different institutional 
incentive structures, while the social psychological literature underlines group-psychological effects. In the following, we will argue that institutional mechanics and psychological factors interact. Thus, they jointly influence group behavior. However, we assume that among the psychological factors, personality traits and not group-psychological factors are of most importance.

In order to make our argument more traceable, we use a concrete social dilemma game, the public goods game, as an illustration. The public goods game is a generalization of the prisoner's dilemma. In the game, actors receive a certain endowment and decide how much of the endowment to contribute to a public good. Contributions to the public good are multiplied by a factor and then evenly divided among all players irrespective of their contributions to the public good. ${ }^{3}$ In addition, actors keep the parts of the endowment not contributed to the public good. Under the common assumptions of rationality and selfishness, keeping the entire endowment is a dominant strategy for each actor. The game is a social dilemma because the social optimum is only reached when all actors fully cooperate and contribute the entire endowment to the public good.

Since the first public goods experiment by Bohm (1972), it is a wellknown fact that participants cooperate more than is predicted by theories assuming pure material self-interest. If the game is played repeatedly over several periods, cooperation levels usually decline in the course of the game, almost reaching the predicted level of zero-contributions in the last periods of play. An important factor explaining this decaying pattern of contributions is the interaction of heterogeneous types of players (Chaudhuri, 2011). Fischbacher et al. (2001) develop an experimental design to identify different types of participants. The largest group consists of conditional cooperators, that is, individuals whose contribution to the public good is positively correlated with the contributions of other subjects. Besides some nonclassifiable participants, there exists also a fraction of free-riders, that is, subjects contributing nothing irrespective of the contributions of other subjects. Usually, the number of free-riders is much smaller than the number of conditional cooperators (e.g. Chaudhuri, 2011; Herrmann and Thöni, 2009; Kocher et al., 2008). ${ }^{4}$ Nevertheless, the presence of even a small number of egoists suffices to crowd out cooperation within a community in the course of several periods because conditional cooperators decrease their own contributions if other subjects free-ride on their contributions and do not contribute to the public good. This sets in motion a negative dynamic as decreasing contributions in one period lead to less cooperation in the following period. Hence, in order to prevent a race to the bottom of contributions and instead maintain high levels of cooperation in a repeatedly played 
public goods game, it is necessary to establish procedures restraining the influence of free-riders as far as possible.

As the first assumption of our model, in line with the research on different types of players in the public goods game, we assume heterogeneous individuals. Thus, communities consist of two types of individuals: conditional cooperators whose cooperation rates are positively correlated with the other actors' cooperation rates in a community and free-riders who do not cooperate in social dilemmas. If the actors in a public goods game are collective actors, these heterogeneous motivations have to be aggregated into a common group decision when the members of a group decide about the group's contribution to the public good. The decision-making rule comes into play as a formal restriction of the decision-making process allocating among other things positive and negative decision power, that is, rights to decide and rights to veto.

Majority rule balances these two rights perfectly: $50 \%$ plus one group members are needed to reach a decision and $50 \%$ plus one group members can block a decision. This creates a dynamic described by the well-known median voter theorem (Black, 1948). In case group members favor different cooperation rates, we can at first identify the median cooperator. In addition, we can identify all members favoring lower contributions than the median cooperator as low cooperators and members favoring higher contributions as high cooperators. Under majority rule, low cooperators and the median cooperator prefer the median cooperator's preferred contribution to the public good to any higher contribution, and vice versa, high cooperators and the median cooperator prefer the median cooperator's preferred contribution to any lower contribution. The median cooperator's desired contribution level dominates all other contribution levels. Thus, there is no winning coalition comprising a majority of group members favoring any contribution level over the median cooperator's desired contribution level. With the median cooperator being the most influential group member, the influence of majority rule on group behavior is conditional on the distribution of preferences in a group. If the majority of group members consist of conditional cooperators, single free-riders can be overruled and the groups will be able to maintain high levels of cooperation in their community. Of course, if the group consists predominantly of egoists, cooperation will be low.

Unanimity rule, however, minimizes the individual right to decide because all group members have effective veto power. Consequently, all group members have to approve the common group decision, and a single egoist in the group could use her veto power to influence the group decision in her desired direction. The same is, of course, true for individual group members with a strong preference for high rates of cooperation. Therefore, 
if we only take formal institutional constraints induced by the voting rule into account, we cannot say whether to expect higher or lower contributions under unanimity rule compared to contributions under majority rule because all contribution levels between the lowest desired contribution in a group and the highest desired contribution are undominated.

At this point, psychological factors come into play. Findings from personality research support the conjecture that under unanimity rule egoistic group members will prevail over more cooperative group members in intragroup decisions. The mainstream psychological concept describing personality structure is the Big-Five Factor Model (see Digman, 1990). According to the model, there are five basic independent dimensions of personality: extraversion (or surgency), agreeableness, conscientiousness (or dependability), emotional stability (vs neuroticism), and openness to experience (or intellect) (Goldberg, 1992). For our study, the second dimension, agreeableness, is of most relevance. Agreeableness is concerned with the motive to maintain positive social relations (Digman and Takemoto-Chock, 1981; Graziano and Eisenberg, 1997; Graziano et al., 1997). It comprises psychological attributes which are essential motivational forces in social dilemma situations, such as unkind versus kind, uncooperative versus cooperative, selfish versus unselfish, and distrustful versus trustful. In addition, agreeableness contains also traits characterizing behavior in conflict situations, such as stubborn versus flexible, inconsiderate versus considerate, and quarrelsome versus agreeable (Goldberg, 1990, 1992: 33). Thus, taken together there is a negative relationship between cooperativeness and stubbornness. Cooperative individuals tend to be accommodating while egoists tend to be more stubborn. Additional evidence comes from Antonioni (1998), who examines relationships between personality traits and different styles of conflict management. One of these styles is dominating. Dominating individuals are characterized as aggressive. They attempt to make sure that only their own needs are met. Thus, "a strong will to achieve one's goals is necessary for using the dominating style; however, when using the dominating style, one's desire to achieve contributes to stubbornness" (Antonioni, 1998: 342). Antonioni finds that the dominating style of conflict management is more common among individuals scoring low on the agreeableness dimension. Graziano and Tobin (2002) also examine attitudes in conflict situations. They show that persons scoring high on agreeableness favor negotiation and disengagement as conflict resolution strategies, whereas persons scoring low on agreeableness prefer power assertion instead.

We argue that under unanimity rule, the negative relationship between cooperativeness and stubbornness comes into effect. If all group members have effective veto power and there is conflict about the group's 
contribution to the public good, the more persisting group members will prevail over the more yielding members. As uncooperative group members are on average more stubborn than cooperative group members, decision making under unanimity rule will thus exhibit a tendency toward lower contributions.

All in all, we thus argue that there is an interaction of the intragroup decision rule and psychological traits. Under unanimity rule, the preferences of all group members must be taken into account, but due to greater stubbornness, egoists assert their preferences more successfully than group members favoring high contributions. Under majority rule, however, the greater stubbornness of egoistic group members does not take effect because the institutional mechanics induces competition between low and high cooperators to reach an agreement with the median cooperator. Hence, insisting on the desired contribution level does not pay off for low and high cooperators under majority rule, because they have to take into account being overruled by the other members of their group. According to this reasoning, we expect that collective actors contribute less to a public good than individual actors when groups decide by unanimity rule. With groups deciding by majority rule, however, we do not expect behavioral differences between individuals and groups.

\section{Experimental design and procedure}

We test our theoretical expectations experimentally in a linear public goods game, also known as the voluntary contribution mechanism (Davis and Holt, 1993: 319). All treatments of the experiment use the same general setting. Figure 1 depicts the structure of a single period of the game. Due to the ambiguity of the term "group," we differentiate between communities and actors. In our experiment, a community consists of four actors. In all treatments, every actor is equipped with an endowment of 20 points in each period, and the task is to decide how to spend these points. An actor can either invest points into a private account or contribute some or all of the points to a community account which is labeled by the neutral term "project." The number of points contributed by actor $i(i=1,2,3,4)$ in period $t$ to the project is $n_{i, t}\left(0 \leq n_{i, t} \leq 20\right)$ with $n_{i, t}$ being an integer. All points not contributing to the community account are automatically transferred into the actor's private account. Actor $i$ 's income $y_{i, t}$ in period $t$ is given by the following equation

$$
y_{i, t}=20-n_{i, t}+0.5 \sum_{k=1}^{4} n_{k, t}
$$






Figure I. Schematic representation of a single round of the experiment.

Each actor earns the points transferred into the private account and half of the sum of all points contributed to the community account. The marginal return from the project is $50 \% .{ }^{5}$ Hence, if all four actors contribute their complete endowment to the project, group welfare will be doubled compared to a situation in which nobody cooperates. No community member is excluded from the distribution of points returned from the community account. Therefore, the project constitutes a public good.

Our experiment comprises three treatments, two group treatments and an individual treatment. In the individual treatment (IT), each actor is a single individual. Hence, IT conforms to the standard public goods game which has been studied extensively in the last three decades. Additionally, we run two group treatments in which actors are groups consisting of three individuals each. In one group treatment, the group majority treatment (GMT), groups decide by majority rule, while we impose unanimity rule in the second group treatment, the group unanimity treatment (GUT). We thus study two treatment variables: the actor type (individual vs collective actors) and the intragroup decision-making rule (majority rule vs unanimity rule).

As in most other experiments comparing group and individual behavior, the amount divided between individual members of a group is simply tripled, and every single group member constituting actor $i$ earns $y_{i, t}$ (e.g. Bornstein et al., 2004; Luhan et al., 2009). This measure is important in order to preserve comparability between treatments for two reasons. First, 
our payment structure ensures that individual participants face identical monetary incentives in all treatments, and second, by implementing equal payments among all members of a group, we eliminate potential distributional conflicts within groups which might bias behavior in a way not controlled for in the experiment.

Of course, a collective actor faces an additional intragroup decision phase in which the actor decides internally over the actor's contribution to the project. Thus, while individual actors in IT enter their contributions to the project directly, group actors in GMT and GUT decide over their contribution $n_{i, t}$ to the project by voting. In GMT, group actors decide by majority rule, while actors in GUT decide by unanimity rule. A group might need several ballots to reach a decision. In both group treatments, each subject has one vote in each ballot and group members cast their vote simultaneously. In GMT, at least two members of a collective actor have to vote for the same contribution to the project in order to reach a decision. If no two members enter an identical $n_{i, t}$ in the first ballot of period $t$, all group members receive information on how the other group members of the same actor have just voted, and a new ballot is held. This procedure is repeated until at least two group members vote for an identical $n_{i, t}$. Analogously, in GUT, all three members of the same actor have to vote for the same contribution to the project. If they cannot reach a unanimous decision in the first ballot of a period, all group members receive information how their fellow group members just voted and a new ballot is held. The voting procedure is repeated until the actor reaches a unanimous decision. Since all actors decide simultaneously, no actor is informed about the contributions of other actors in the current period while still deciding on its own contribution. Not before all actors have made their decisions, subjects learn about the contributions of the other actors in their community and the distribution of points earned in the current period.

The game is repeated for 15 periods applying a partner-matching procedure to assign actors into communities. Partner matching implies that in all three treatments a single community consists of the same four actors throughout the whole experiment. Additionally, we also apply partner matching to form group actors in the two group treatments. Hence, groups consist of the same three individual subjects throughout the 15 periods of play. Our experimental setting thus mirrors social dilemma situations frequently found in the field where the same actors typically interact repeatedly over a longer period of time. In order to isolate the effect of the decision rule from confounding factors like direct face-to-face communication, subjects interact anonymously via a computer network. Communication between subjects is thus restricted to entering their votes. 


\section{Experimental results}

We ran the experiments from November 2008 to January 2009 in the Cologne Laboratory for Economic Research using the software z-Tree (Fischbacher, 2007). Subjects were invited via email employing the Online Recruitment System for Economic Experiments (ORSEE) (Greiner, 2004). ${ }^{6}$ Each of the 344 subjects participating in our study took part only once. A total of 144 subjects formed 12 communities in both GMT and GUT, while the 14 communities in IT consisted of 56 subjects. All of our participants were students from the University of Cologne, most of them $(71.5 \%)$ students of economics, management, or related fields. After arriving at the laboratory, subjects were randomly assigned to cubicles where they read the instructions. ${ }^{7}$ The instructions to the experiment are written in neutral context free language in order not to influence subjects' behavior in a certain direction. Any questions were answered privately. We used a short questionnaire to test whether all participants understand the instructions correctly. In this questionnaire, subjects were also asked to calculate the resulting payoffs of several hypothetical numerical examples of contributions to the project to make sure that they completely understand the game's dilemma structure. At the end of the experiment, subjects filled in a second questionnaire surveying demographical data like gender, age, and field of study.

Participants were paid in cash individually and privately. They received $€ 0.10$ per six points earned during the experiment. Including a show-up fee of $€ 2.50$, participants earned on average $€ 10.52$. The experiment lasted about 1 hour. Hence, payoffs are equivalent to or higher than the average local per hour wage of $€ 8$ to $€ 10$ for jobs typically offered to students.

The analysis of our experimental findings proceeds in three parts. First, we compare aggregate contribution levels across treatments. Afterwards, we analyze how actors adjust their contributions to the project in the course of the experiment, and finally, we focus on intragroup decision making in the two group treatments.

Figure 2 depicts mean contributions per period to the project in the three treatments. In all treatments, the development of contributions shows a typical pattern which can also be found in comparable experiments studying the voluntary contribution mechanism. Overall, we find high levels of cooperation in all treatments. On average, actors contribute 12.19 points $(60.94 \%$ of their endowment) to the project. Starting with even higher contributions around 15 points in the first period, contributions decline steadily over the course of the experiment. In the last three periods, there is an end-game effect with rapidly declining contributions in all treatments. 


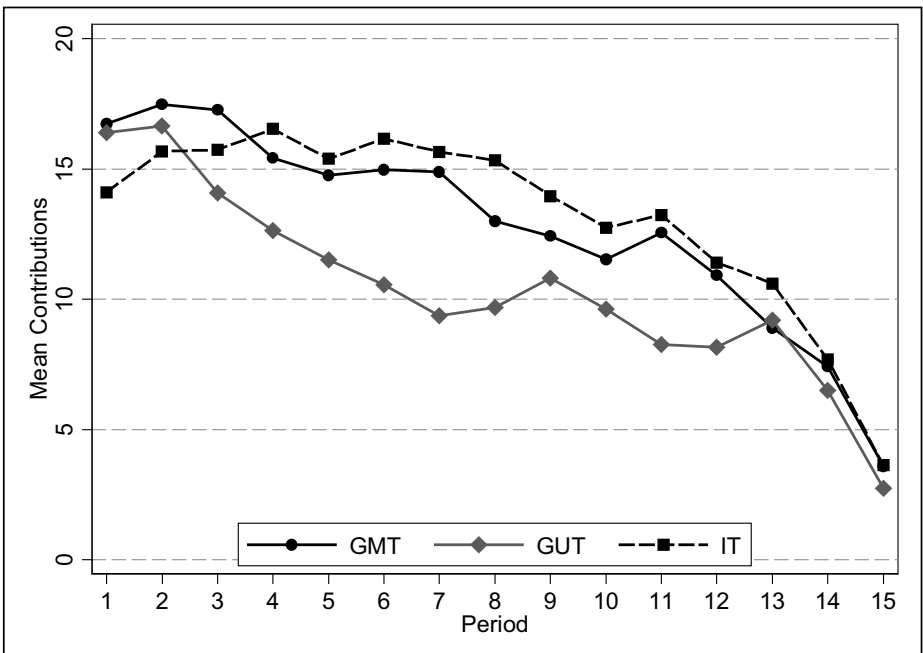

Figure 2. Mean contributions to the project.

Despite these similar general patterns of play, there are also important differences between the treatments. Contributions are highest in IT, where individual actors contribute on average 13.19 points. Group actors in GMT contribute only slightly less (12.79 points), whereas contributions in GUT are substantially lower (10.41 points). If all 15 periods of the experiment are considered, these differences are not significant across all three treatments $(p$ $=0.153$; two-sided Kruskal-Wallis Test) ${ }^{8}$ A pairwise test, though, reveals a (weakly) significant difference between GUT and IT ( $p=0.080$; two-sided Mann-Whitney U-test). The differences between GMT and IT and between GMT and GUT do not reach commonly accepted levels of significance ( $p=$ $0.572, p=0.133$, respectively; two-sided Mann-Whitney U-tests).

Figure 2 also reveals that subjects' behavior changes in the course of the experiment. For instance, in the first period of the experiment, collective actors in both group treatments cooperate significantly more than individual actors in IT (GMT-IT: 16.73 vs 14.11 points, $p=0.059$; GUT-IT: 16.40 vs 14.11 points, $p=0.084$; two-sided Mann-Whitney U-tests). In the following periods, individuals in IT increase their contributions slightly, whereas in GUT contributions to the project decline rapidly. Groups in GMT, however, are able to stabilize the level of cooperation around $75 \%$ of the endowment, so that initial differences between GMT and IT vanish.

The end-game effect in the last three periods of the experiment conceals more distinct behavioral differences in the preceding periods of the game. ${ }^{9}$ Thus considering only periods 1 to 12 , individual actors in IT contribute 
14.66 points, group actors in GMT 14.33 points, and group actors in GUT 11.48 points. The difference between mean contributions in the first 12 periods is significant at the $10 \%$ level ( $p=0.099$; two-sided Kruskal-Wallis Test). Moreover, pairwise tests reveal significant differences between GUT and IT and between GUT and GMT ( $p=0.054, p=0.089$, respectively; two-sided Mann-Whitney U-tests), but no significant difference between GMT and IT ( $p=0.571$; two-sided Mann-Whitney U-test).

Differences between treatments are driven by a considerable variance in the occurrence of full cooperation, that is, contributions of 20 points to the project. Whereas $49.29 \%$ of the actor decisions in IT and $40.42 \%$ in GMT result in a contribution of the full endowment of 20 points, the frequency of full cooperation is only $24.72 \%$ in GUT. The difference is significant ( $p=$ 0.073; two-sided Kruskal-Wallis Test).

Overall, this first analysis of mean contributions to the project shows an effect of the intragroup decision-making rule on group behavior. Group and individual behavior do not differ per se, but the incentives set by majority and unanimity rule lead to different results in GMT and GUT compared to IT. While groups deciding by majority rule reach roughly the same level of cooperation as individual actors in IT, groups deciding by unanimity rule contribute significantly lower amounts to the public good. Our findings thus contradict the theoretical reasoning on the basis of the social psychological discontinuity effect, according to which we expected highest contributions in IT and lowest contributions in GMT with contributions in GUT inbetween. Instead, aggregate behavior seems to be in line with our explanation, assuming an interaction between the institutional incentive structure and personality traits. We predicted lower contribution levels in GUT because of the greater stubbornness of more egoistic group members. Following this argument, we should find different patterns of intragroup decision making. In the following, we will proceed by analyzing the dynamics of play, especially the adjustments of contributions to the project in the course of the experiment and within-group decision making in the two group treatments.

\section{Adjustment of actors' contributions in the course of play}

As a next step in our analysis of the differences between treatments, we turn to the dynamics of play. At the end of each period, actors learn the contributions of the other actors in their community. As we argue above, conditional cooperators adjust their desired contributions in light of the contributions of other actors in their community. Hence, if the other actors contribute more, a conditional cooperator will increase her own contribution and vice versa decrease her contributions if the other actors in her community contribute 
less. In a series of regressions, we investigate how actors adjust their contributions between two periods. We use the following regression equation

$$
\begin{aligned}
\text { Contribution }_{i, t}= & \alpha_{0}+\beta_{1} \text { Period }_{t}+\beta_{2} \text { Contribution }_{i, t-1}+ \\
& \beta_{3} \text { Lowest contribution in community }_{i, t-1}+ \\
& \beta_{4} \text { Highest contribution in community } \\
i, t-1 & +u_{i, t}
\end{aligned}
$$

Our dependent variable Contribution $_{i, t}$ is the contribution of an actor $i$ in period $t$. As independent variables, we include the current period number to control for the time trend apparent in the data and the actor's contribution from the previous period, $t-1$. Furthermore, we include the lowest contribution in the community in period $t-1$ and the highest contribution in the community in the previous period in order to test whether actors are responsive to the contributions of the other actors in their community. ${ }^{10}$

Table 1 shows the regression results. In all treatments, the period number has a highly significant negative effect on contributions. The contribution in $t-1$, however, only has a significant influence on the actor's current contribution in IT. In the two group treatments, the group's contribution in the previous period does not affect a group's contribution in the current period. A likely explanation for this phenomenon is the influence of intragroup decision making. Actors in IT enter their contributions directly and it is thus not surprising that there is a highly significant relationship between the contributions of consecutive periods. In the two group treatments, this relationship is distorted by the requirement to reach a binding group decision. The fact that an actor's contribution in period $t-1$ does not significantly influence the actor's contribution in period $t$ underlines the importance of intragroup decision making for the behavior of collective actors.

The lowest contribution of all actors in the community in the previous period has a highly significant influence in all three treatments. Hence, irrespective of the actor type and the decision-making rule in place, actors contribute less the lower the lowest contribution in their community. This can be interpreted as evidence for the presence of conditional cooperators in our experiment who display negative reciprocity by decreasing their contributions as a reaction to low cooperation rates in their community. In IT we also find evidence for positive reciprocity. The significant coefficient of the highest contribution in the community in period $t-1$ indicates that actors increase their contributions as a reaction to high levels of cooperation in their community. In GMT, this effect is only weakly significant, whereas it is completely insignificant in GUT. The complete absence of positive reciprocity is a possible explanation for lower contributions in GUT in comparison to the other two treatments. Apart from that, the patterns of adjustment 
Table I. Adjustments of actors' contributions to the project.

\begin{tabular}{|c|c|c|c|}
\hline $\begin{array}{l}\text { Dependent variable: } \\
\text { Contribution }_{t}\end{array}$ & IT & GMT & GUT \\
\hline Period & $-0.432(0.091)^{* * *}$ & $-0.389(0.060)^{* * *}$ & $-0.331(0.066) * * *$ \\
\hline Contribution $_{t-1}$ & $0.190(0.062)^{* * *}$ & $0.115(0.070)$ & $0.114(0.067)$ \\
\hline Lowest contribution & $0.330(0.047)^{* * *}$ & $0.437(0.050)^{* * *}$ & $0.445(0.076)^{* * *}$ \\
\hline $\begin{array}{l}\text { in community } \text { co }_{t} \text { I } \\
\text { Highest contribution } \\
\text { in community }\end{array}$ & $0.324(0.091)^{* * *}$ & $0.144(0.072) *$ & $0.096(0.068)$ \\
\hline Constant & $5.473(2.520) * *$ & $7.863(1.310)^{* * *}$ & $7.56 \mathrm{I}(\mathrm{I} .62 \mathrm{I})^{* * *}$ \\
\hline$R^{2}$ & 0.492 & 0.440 & 0.370 \\
\hline$N$ & 784 & 672 & 672 \\
\hline
\end{tabular}

IT: individual treatment; GMT: group majority treatment; GUT: group unanimity treatment. $*(* *)[* * *]$ Statistically significant at the $0.10(0.05)$ [0.01] level (two-tailed).

Parentheses contain robust standard errors clustered by community with 14 clusters in IT and 12 clusters in GMT and GUT.

of contributions in the two group treatments are quite similar. It is thus likely that differences between treatments are caused by other factors. Therefore, in a next step, we turn toward analyzing intragroup decision making in the two group treatments.

\section{Within-group decision making}

Neither in GMT nor in GUT, groups have severe problems reaching a decision. In GMT, it takes on average 1.73 ballots to reach a decision. There is a remarkable proportion of immediate agreement in GMT. A total of $65.56 \%$ (472 out of 720 group decisions) of all actors deciding by majority rule come to a decision in the first ballot of a period. The phenomenon of immediate agreement appears from the first period on and remains present throughout the whole experiment. It occurs most often in those communities which maintain full cooperation throughout a substantial number of periods. In GUT, where unanimity rule assigns veto power to all group members, group actors need more ballots to agree on a common contribution to the project. Thus, in GUT the mean number of ballots is 5.69 and only $15.42 \%$ (111 out of 720) reach a unanimous decision in the first ballot.

According to our theoretical argument presented above, we expect that under majority rule in GMT the group's median cooperator will be able to enforce her desired contribution level as the group's decision. Under unanimity rule, all group members have effective veto power. Therefore, if we take only the institutional incentive structure into account, we expect group decisions in GUT resembling a compromise between all three group 
members. In particular, no specific group member will dominate the group decision, but all group members will have a significant influence when deciding on the group's contribution to the project. However, if our theoretical reasoning is true that due to their greater stubbornness, more egoistic group members use their veto power more effectively than more cooperative group members, we should observe that egoistic group members exert a greater influence during intragroup decision making than cooperative group members.

For our analysis of the influence of individual group members on group decision making, we run a series of regression models with actors' contributions in period $t$ as the dependent variable using the following equation

$$
\begin{aligned}
\text { Contribution }_{i, t}= & \alpha_{0}+\beta_{1} \text { Period }_{t}+\beta_{2} \text { Low }_{\text {preference }} \text { f }_{i, t}+ \\
& \beta_{3} \text { Median preference }_{i, t}+ \\
& \beta_{4} \text { High preference }_{i, t}+u_{i, t}
\end{aligned}
$$

To determine the influence of individual group members on the withingroup decision, we have to identify the group members' desired contribution levels in a period. As a proxy, we take the individual votes in the first ballot held in a period. We rank the members of a group according to their first vote and thus identify low, median, and high cooperators in each group in each period. ${ }^{11}$ Thus, Low cooperator ${ }_{i, t}$ is the lowest initial vote of the members of actor $i$ in period $t$. Median cooperator ${ }_{i, t}$ and High cooperator ${ }_{i, t}$ are defined analogously. We also insert the current period number to adjust for the time trend in the data. ${ }^{12}$

Regression results are summarized in Table $2 .{ }^{13}$ First, we concentrate on majority decision making in GMT. Overall, the regression results provide ample support for our claim that the median cooperator enforces her desired contribution as the group's decision. The coefficient of Median cooperator is highly significant and of substantial size, whereas the coefficients of Low cooperator and High cooperator do not reach commonly accepted levels of significance. Thus, the median cooperator is the only group member with a significant influence on majority decision making, just as our model predicts. This pattern shows empirically that majority rule vests the median player with a strategically favorable position. Rather than having to depart from her initial preference and opting for a more competitive or more cooperative choice, the median player in GMT can stick to her initial preference and wait for one of the other two players to adjust to her choice.

The analysis of the final votes in each period provides further evidence that in our experimental setting majority rule does not generally promote cooperative or egoistic tendencies in a group. In 137 of 720 majority 
Table 2. Influence of individual group members on within-group decision making.

\begin{tabular}{lcc}
\hline $\begin{array}{l}\text { Dependent variable: } \\
\text { Contribution }\end{array}$ & GMT & GUT \\
\hline Period & $-0.192(0.095)^{*}$ & $-0.086(0.043)^{*}$ \\
Low cooperator $_{t}$ & $0.201(0.121)$ & $0.315(0.038)^{* * * *}$ \\
Median cooperator $_{t}$ & $0.723(0.082)^{* * * *}$ & $0.644(0.043)^{* * *}$ \\
High cooperator $_{t}$ & $0.057(0.120)$ & $0.132(0.061)^{*}$ \\
Constant $^{2}$ & $1.967(1.487)$ & $0.289(0.834)$ \\
$R^{2}$ & 0.398 & 0.703 \\
$N$ & 248 & 609 \\
\hline
\end{tabular}

GMT: group majority treatment; GUT: group unanimity treatment.

*(**) [***] Statistically significant at the $0.10(0.05)$ [0.0I] level (two-tailed).

Parentheses contain robust standard errors clustered by community with 14 clusters in IT and 12 clusters in GMT and GUT.

decisions, there is a unanimous consent of all three group members over the group's contribution. This leaves 583 group decisions in which a majority of two group members overrules the third member. In 266 of these 583 decisions, the overruled group member favors a higher contribution, and 317 times a more egoistic group member is overruled. The difference is not significant $\left(p=0.387\right.$; two-sided Wilcoxon Test) ${ }^{14}$ which again shows the attraction of the median's desired contribution level and the resulting mediating effect of majority rule on cooperation between groups. Obviously, low and high cooperators compete equally to reach an agreement with median cooperators.

Behavioral patterns of intragroup decision making under unanimity rule in GUT differ considerably from the patterns found in GMT. As in GMT, our regression results for GUT identify a highly significant influence of the median cooperator during intragroup decision making. However, we also find a significant influence of the most egoistic group member under unanimity rule. Although a comparison of the regression coefficients reveals that the influence of the low cooperator is substantively smaller than the median's influence, the most cooperative group member only has a weakly significant influence on intragroup decision making and the effect is again substantively smaller than the low cooperator's influence. The regression results thus show that low cooperators are less compromising than high cooperators. The fact that low cooperators are more influential in GUT is a clear sign of greater stubbornness of low cooperators. The dynamics of intragroup decision making thus explain the lower contributions in GUT because low cooperators use their veto power more effectively to pull contributions downward. Overall, we can thus reject the hypothesis that decisions in GUT are a compromise between all group members. Instead, our 
results are in line with the theoretical reasoning that because of the greater stubbornness of low cooperators decision making under unanimity rule exhibits a systematical bias toward lower cooperation rates.

\section{Conclusion}

In our experiment, we study individual actors, three-person groups deciding by majority rule, and three-person groups deciding by unanimity rule in a comparable linear public goods setting. Our experimental results show that there is no generic difference between individual and group behavior. Instead, the within-group decision-making rule has an influence on cooperation between groups. Groups deciding by unanimity rule cooperate less than groups deciding by majority rule. The experimental results presented in this article support the theoretical argument that there is an interaction between institutional mechanics and personality traits. Formal intragroup decision-making rules determine group decisions with a different degree of certainty (see North, 1990). In our setting, majority rule greatly diminishes uncertainty about the outcome of the within-group decision-making process by generating competition between the more egoistic and the more cooperative group member to reach an agreement with the group's median cooperator. The median player can enforce her desired contribution level by just waiting for the other group members to adjust to her will. Hence, the decision-making rule alone already determines an exact outcome and promotes neither more egoistic nor more cooperative decisions in GMT compared to behavior in IT.

Unanimity rule, however, usually leaves the exact group decision undetermined because all group members have effective veto power. This indeterminacy of unanimity rule opens an opportunity space for personality traits of individual group members to take effect. The analysis of the intragroup decision-making process supports our claim. In particular, more egoistic group members tend to be more stubborn than more cooperative group members. Under the requirement of a unanimous group decision, more egoistic group members use their veto power more effectively to influence the outcome of the decision-making process in their preferred direction, whereas more cooperative group members restrain from using their own veto power to counter the influence of more egoistic group members.

Prior work has shown that unanimity rule in conjunction with an existing status quo might lead to the preservation of inefficient policies (e.g. Scharpf, 1988). Under unanimity rule, a small fraction of a community can block any decision or demand substantial concessions in exchange for their consent even if a large majority profited from a proposed policy shift. Our experimental results show that decision making under unanimity rule can result in 
welfare-inferior outcomes even in situations without a predefined status quo. Additionally, our findings have important implications for the application of the unitary actor assumption, that is, treating groups as individual actors. Being an important tool for simplification in order to keep models tractable, the unitary actor assumption should be employed with caution though. Our results emphasize that depending on the intragroup decisionmaking process in place, the behavior of collective actors might systematically differ from the behavior of individual actors. We thus regard our study as an important step in order to gain an essential deeper understanding of group behavior.

A relevant question not covered in this study concerns the effect of communication in between-group interactions. In order to determine the influence of the decision rule, our experimental design implements anonymous interactions within and between groups. We prohibit direct face-to-face interactions because these might have independent, barely controllable effects on the subjects' willingness to cooperate. Most real-world interactions, however, involve face-to-face encounters between involved actors, and it would be interesting to see whether the possibility to communicate in groups gives a stronger voice to egoists or to cooperators. Hence, studying the effect of intra- and intergroup communication and its interactions with the within-group decision-making rules is obviously a promising avenue for future research on group behavior in social dilemmas.

\section{Acknowledgements}

The project was presented at different stages at the "Experimental Political Science Workshop" (Hanse Wissenschaftskolleg Delmenhorst, 2008) and the European Consortium for Political Research (ECPR) Joint Sessions of Workshops, Workshop "Voting Experiments" (St Gallen, 2011). We would also like to thank our colleagues at the Cologne Center for Comparative Politics for many helpful comments and suggestions.

\section{Funding}

This work received generous funding from the Fritz Thyssen Stiftung für Wissenschaftsförderung (Az. 20.08.0.101). Financial support from the Deutsche Forschungsgemeinschaft (DFG) for the Cologne Laboratory for Economic Research is also gratefully acknowledged.

\section{Notes}

1. Luhan et al. (2009) use the decisions made in the dictator game played between individuals to identify the group members' type. The group member having transferred the lowest amount in the dictator game played between individuals is identified as the most selfish group member. 
2. Blinder and Morgan (2005), who compare individuals and groups in a pure problem-solving task with an objectively correct solution, find something similar. Team members interact face-to-face with either majority rule or unanimity rule as the formally implemented decision rule. They find that groups make qualitative superior decisions compared to individuals. However, behavioral differences between groups vanish as majority decisions quickly evolve into unanimous decisions.

3. The factor is greater than 1 and smaller than the number of actors.

4. On the reception of the concept of conditional cooperation in the political science literature, see Hibbing and Alford (2004) and Smith (2006).

5. In a community consisting of four actors, an incentive to free-ride emerges if the marginal return from the project is between 0.25 and 1 . So from the theoretical perspective, the concrete parameterization of the experiment does not matter as long as the parameters are constant across treatments. We choose a marginal return rate of 0.5 merely for pragmatically reasons; employing a factor of 0.5 simplifies the calculation of profits, and we thus minimize the risk that participants commit computational errors which might bias our experimental results.

6. The complete pool from which we recruited our participants comprises more than 2700 registered subjects. Nearly all of them are students from the University of Cologne, and the majority students are from the faculty of management, economics, and social sciences.

7. Instructions used in group majority treatment (GMT) may be found in the Appendix 1. The adapted instructions of individual treatment (IT) and group unanimity treatment (GUT) can be obtained from the authors upon request.

8. Unless otherwise indicated, all statistical tests use communities as independent units of observation.

9. While in GMT and IT, the end-game effect is clearly present in the final three periods of the experiment, average contributions in GUT increase between periods 12 and 13. One could thus argue that the end-game effect is only present in the last two periods. We therefore tested whether excluding only the final two periods changes the findings. The results stay virtually the same.

10. In order to test whether our regression models suffer from multicollinearity, we calculate variance inflation factors. The results show that multicollinearity is neither a problem in IT, GMT, nor in GUT. In all models, the variance inflation factors of all regressors are below the value of 2.5 .

11. We rank group members separately for each period of the experiment. In order to test for the stability of the rankings of group members across the 15 periods of the experiment, we conduct Skillings-Mack tests. The test reveals constant significant differences between the rankings of group members in 69 out of 96 groups in GMT and GUT.

12. We again test for multicollinearity by calculating variance inflation factors. In both models, the variance inflation factors of all regressors are below the value of 2.2 .

13. If a group needs only one ballot to reach a decision in GMT, the group's contribution must be equal to Median cooperator ${ }_{i, t}$ In GUT a group's contribution 
must be equal to Low cooperator ${ }_{i, t}$ Median cooperator ${ }_{i, t}$, and High cooperator ${ }_{i, t}$ in case of immediate agreement. Therefore, we only consider group decisions in which groups vote more than once in order to reach a binding decision.

14. We compare the number of times an overruled group members in a community favor a higher contribution to the project with the number of times they favor a lower contribution.

\section{References}

Abbink K, Brandts J, Herrmann B, et al. (2010) Intergroup conflict and intra-group punishment in an experimental contest game. American Economic Review 100: 420-447.

Antonioni D (1998) Relationship between the big five personality factors and conflict management styles. International Journal of Conflict Management 9: 336-355.

Black D (1948) On the rationale of group decision making. Journal of Political Economy 56: 23-34.

Blinder AS and Morgan J (2005) Are two heads better than one? Monetary policy by committee. Journal of Money, Credit, and Banking 37: 789-811.

Bohm P (1972) Estimating demand for public goods: an experiment. European Economic Review 3: 111-130.

Bornstein G (2003) Intergroup conflict: individual, group, and collective interests. Personality and Social Psychology Review 7: 129-145.

Bornstein G and Ben-Yossef M (1994) Cooperation in intergroup and single-group social dilemmas. Journal of Experimental Social Psychology 30: 52-67.

Bornstein G and Yaniv I (1998) Individual and group behavior in the ultimatum game: are groups more "rational" players? Experimental Economics 1: 101108.

Bornstein G, Kugler T and Ziegelmeyer A (2004) Individual and group decisions in the centipede game: are groups more "rational" players? Journal of Experimental Social Psychology 40: 599-605.

Bosman R, Hennig-Schmidt H and van Winden F (2006) Exploring group decision making in a power-to-take experiment. Experimental Economics 9: 35-51.

Cason TN and Mui V-L (1997) A laboratory study in group polarisation in the team dictator game. Economic Journal 107: 1465-1483.

Chaudhuri A (2011) Sustaining cooperation in laboratory public goods experiments: a selective survey of the literature. Experimental Economics 14: 47-83.

Coleman E and Ostrom E (2011) Experimental contributions to collective action theory. In: Druckman JN, Green DP, Kuklinski JH, et al. (eds) Cambridge Handbook of Experimental Political Science. Cambridge: Cambridge University Press, pp. 339-352.

Cox JC (2002) Trust, reciprocity, and other-regarding preferences: groups vs. individuals and males vs. females. In: Zwick R and Rapoport A (eds) Experimental Business Research. Dordrecht: Kluwer Academic Publishers, pp. 331-349.

Davis DD and Holt CA (1993) Experimental Economics. Princeton, NJ: Princeton University Press. 
Digman JM (1990) Personality structure: emergence of the five-factor model. Annual Review of Psychology 41: 417-440.

Digman JM and Takemoto-Chock NK (1981) Factors in the natural language of personality: re-analysis, comparison, and interpretation of six major studies. Multivariate Behavioral Research 16: 149-170.

Eliaz K, Ray D and Razin R (2006) Choice shifts in groups: a decision-theoretic basis. American Economic Review 96: 1321-1332.

Fischbacher U (2007) z-Tree: Zurich toolbox for ready-made economic experiments. Experimental Economics 10: 171-178.

Fischbacher U, Gächter S and Fehr E (2001) Are people conditionally cooperative? Evidence from a public goods experiment. Economics Letters 71: 397-404.

Gillet J, Schram AJHC and Sonnemans J (2009) The tragedy of the commons revisited: the importance of group decision-making. Journal of Public Economics 93: 785-797.

Goldberg LR (1990) An alternative "description of personality": the big-five factor structure. Journal of Personality and Social Psychology 59: 1216-1229.

Goldberg LR (1992) The development of markers for the big-five factor structure. Psychological Assessment 4: 26-42.

Graziano WG and Eisenberg N (1997) Agreeableness: a dimension of personality. In: Hogan R, Johnson J and Briggs S (eds) Handbook of Personality Psychology. San Diego, CA: Academic Press, pp. 795-824.

Graziano WG and Tobin RM (2002) Agreeableness: dimension of personality or social desirability artifact? Journal of Personality 70: 695-727.

Graziano WG, Hair EC and Finch JF (1997) Competitiveness mediates the link between personality and group performance. Journal of Personality and Social Psychology 73: 1394-1408.

Greiner B (2004) An online recruitment system for economic experiments. In: Kremer K and Macho V (eds) Forschung und wissenschaftliches Rechnen 2003 (GWDG Bericht 63). Göttingen: Gesellschaft für Wissenschaftliche Datenverarbeitung, pp. 79-93.

Herrmann B and Thöni C (2009) Measuring conditional cooperation: a replication study in Russia. Experimental Economics 12: 87-92.

Hibbing JR and Alford JR (2004) Accepting authoritative decisions: humans as wary cooperators. American Journal of Political Science 48: 62-76.

Kocher MG and Sutter M (2007) Individual versus group behavior and the role of the decision making procedure in gift-exchange experiments. Empirica 34: 63-88.

Kocher MG, Cherry TL, Kroll S, et al. (2008) Conditional cooperation on three continents. Economics Letters 101: 175-178.

Kugler T, Bornstein G, Kocher MG, et al. (2007) Trust between individuals and groups: groups are less trusting than individuals but just as trustworthy. Journal of Economic Psychology 28: 646-657.

Ledyard JO (1995) Public goods: a survey of experimental research. In: Kagel JH and Roth AE (eds) The Handbook of Experimental Economics. Princeton, NJ: Princeton University Press, pp. 111-194. 
Luhan WJ, Kocher MG and Sutter M (2009) Group polarization in the team dictator game reconsidered. Experimental Economics 12: 26-41.

North DC (1990) Institutions, Institutional Change and Economic Performance. Cambridge: Cambridge University Press.

Ostrom E (1999) Coping with tragedies of the commons. Annual Review of Political Science 2: 493-535.

Scharpf FW (1988) The joint-decision trap: lessons from German federalism and European integration. Public Administration 66: 239-278.

Schopler J and Insko CA (1992) The discontinuity effect in interpersonal and intergroup relations: generality and mediation. In: Stroebe $\mathrm{W}$ and Hewstone $\mathrm{M}$ (eds) European Review of Social Psychology. Chichester: Wiley, pp. 121-151.

Smith KB (2006) Representational altruism: the wary cooperator as authoritative decision maker. American Journal of Political Science 50: 1013-1022.

Wildschut T and Insko CA (2007) Explanations of interindividual: intergroup discontinuity: a review of the evidence. European Review of Social Psychology 18: 175-211.

Wildschut T, Pinter B, Vevea JL, et al. (2003) Beyond the group mind: a quantitative review of the interindividual-intergroup discontinuity effect. Psychological Bulletin 129: 698-722.

\section{Appendix I}

\section{Experimental instructions}

This appendix contains an English translation of the instructions used in the group majority treatment. The adapted instructions of the other treatments and the original German versions of the instructions can be obtained from the authors upon request.

Instructions. Welcome to today's experiment. In the course of the experiment, you will have the opportunity to earn money. How much you earn depends on your decisions during the experiment. Your decisions remain anonymous to the other participants of the experiment.

In any case, every participant receives a show-up fee of $€ 2.50$. Additionally, you have the opportunity to earn points in every period of the experiment. After the last period, all points that you have earned in the course of the experiment will be summed up. These points will be converted into cents in the ratio of 6:10. For 60 points, for example, you will get $€ 1.00$ in addition to the $€ 2.50$ show-up fee. The money will be paid out in cash at the end of the experiment. Each participant only gets to know her own final payoff.

During the experiment, communication with other participants is not allowed. Please do not ask questions openly! If anything is unclear, 
please give us a hand signal. We will come to your place and resolve the problem in private.

The course of the experiment in detail. In this experiment, you will be member of a group of three. Your group interacts with three other groups, and thus, there are always four groups interacting with each other. You will not get to know the identity of other participants of the experiment. The experiment consists of $\mathbf{1 5}$ decision periods. In every period of the experiment, the procedure is the same. The structure of a period will be explained below. The composition of each group does not change during the entire experiment. Thus, you will form a group with the same two other participants during all 15 periods. Your group will always interact with the same three other groups, whose composition will not change either.

The task. You will face the same task in each of the experiment's 15 periods. In every period, each group receives an endowment of 20 points. Your group has to decide how to use these 20 points. The details of the group's decision-making process will be explained later. Your group can either keep the 20 points to yourselves or contribute some or all of the points to a project. Your group keeps every point not contributed to the project automatically to yourselves. Your income consists of two components. In each of the 15 periods, you receive income from the retained points and income from the project.

Your income from the retained points. For every point that your group keeps to yourselves, each member of the group receives exactly one point. For example, if your group decides to keep all of the 20 points in a period, and hence, contribute no points to the project, you and the other members of your group will receive an income of 20 points from the points kept in this period. If your group decides to contribute 8 points to the project, you and the other members of your group will receive an income of 12 points from the retained points. Members of the other three groups receive no income from the points retained by your group.

Your income from the project. Your income from the project is

Your income from the project $=$ Sum of contributions of all four groups $\times 0.5$

For each point contributed to the project by your group or any of the three other groups, you, the 2 other members of your group, and each 
member of the other groups you are interacting with receive 0.5 points. Let us assume group 1 contributes 13 points to the project, group 2 contributes 19 points, group 3 contributes 0 points, and group 4 contributes 6 points. In this case, the sum of all contributions amounts to $13+19+0+6=38$ points. You, the other members of your group, and the members of the other three groups you are interacting with each receive an income of $0.5 \times 38$ points $=19$ points from the project in the period.

The calculation of the income is identical for each member of all four groups. Thus, every member of your group and every member of the other three groups receive an identical income from the contributions to the project.

Your total income. Your total income in a period is the sum of your income from the retained points and the income from the project. For instance, if your group contributes 14 points to the project, and the other three groups contribute 38 points in total to the project, the total sum of all contributions to the project is 52 points. In this period, your income from the retained points is 6 points, and the income from the contributions to the projects amounts to $0.5 \times$ $52=26$ points. All in all, you would have earned 32 points in the period.

The decision-making process within your group. In every period, your group has to decide by voting how many points out of your endowment of 20 points your group wants to contribute to the project. Every point not contributed to the project is automatically kept by your group. In every ballot, each group member has one vote. Your group decides by majority rule. This means that an absolute majority of the members of your group-at least two - has to vote for an identical contribution to project in order to determine the group's contribution to the project. Possibly, your group has to vote more than once in a period, until at least two group members vote for an identical contribution to the project. In the following, we will explain the details of the voting process. At the beginning of a period, all group members will see the screen as in Figure 3.

At the top left of your screen, you can see the current period of the experiment. In the box below, you are asked to vote on the number of points you want your group to contribute to the project. You are given the information that the endowment of your group amounts to 20 points. In the box below, you can cast your vote. Please enter the amount that you want to contribute to the project in the box that says, "Your desired contribution." You can enter your vote by clicking on the box.

You can only contribute integer numbers to the project. Your desired contribution has to be an integer number between 0 and 20 (e.g. $0,1,2,3,4, \ldots, 17$, $18,19,20)$. A contribution of 6.3 points, for example, is not possible. If you 


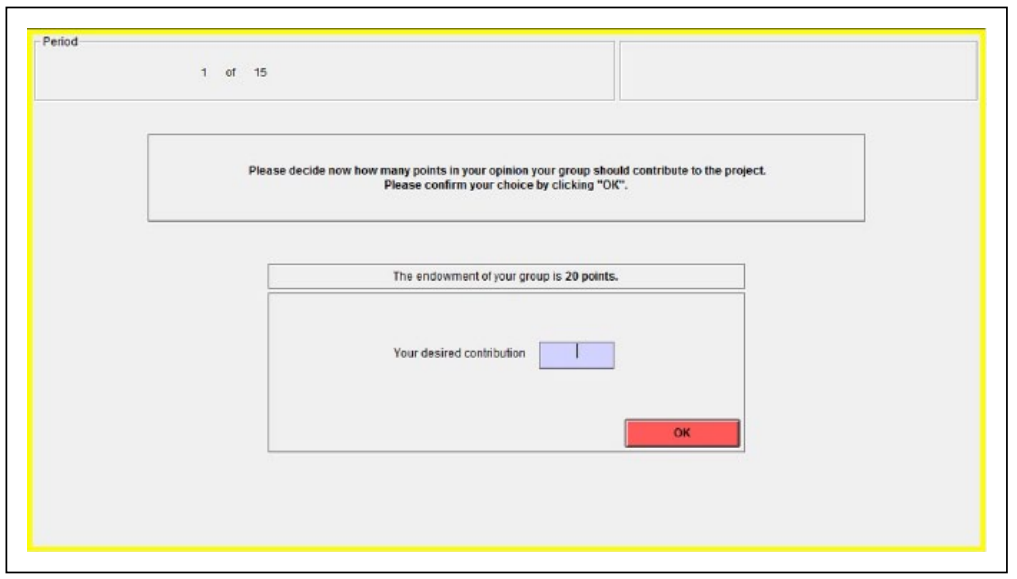

Figure 3.

enter an inadmissible number, the program will notify you and ask you to enter an integer number. To confirm your vote, click the "OK" button. Please remember to confirm your vote by clicking the "OK" button; otherwise the computer cannot process your vote, and the experiment cannot proceed.

After you cast your vote, the box in which you entered your decision disappears. You are asked to wait until all other group members have cast their vote. The votes of every member of your group are cast simultaneously in every period. Not before all group members have cast their votes, you will get to know how the other members of your group have decided.

The proceeding of the experiment depends on the results of the last ballot held in the current period.

After a ballot, two cases can occur.

- No contribution gets an absolute majority of two or more votes.

- One amount of points is chosen by an absolute majority of the group members.

Both cases will be explained successively.

Case 1: No contribution gets an absolute majority of two or more votes.

In this case, you will see the screen as in Figure 4. 


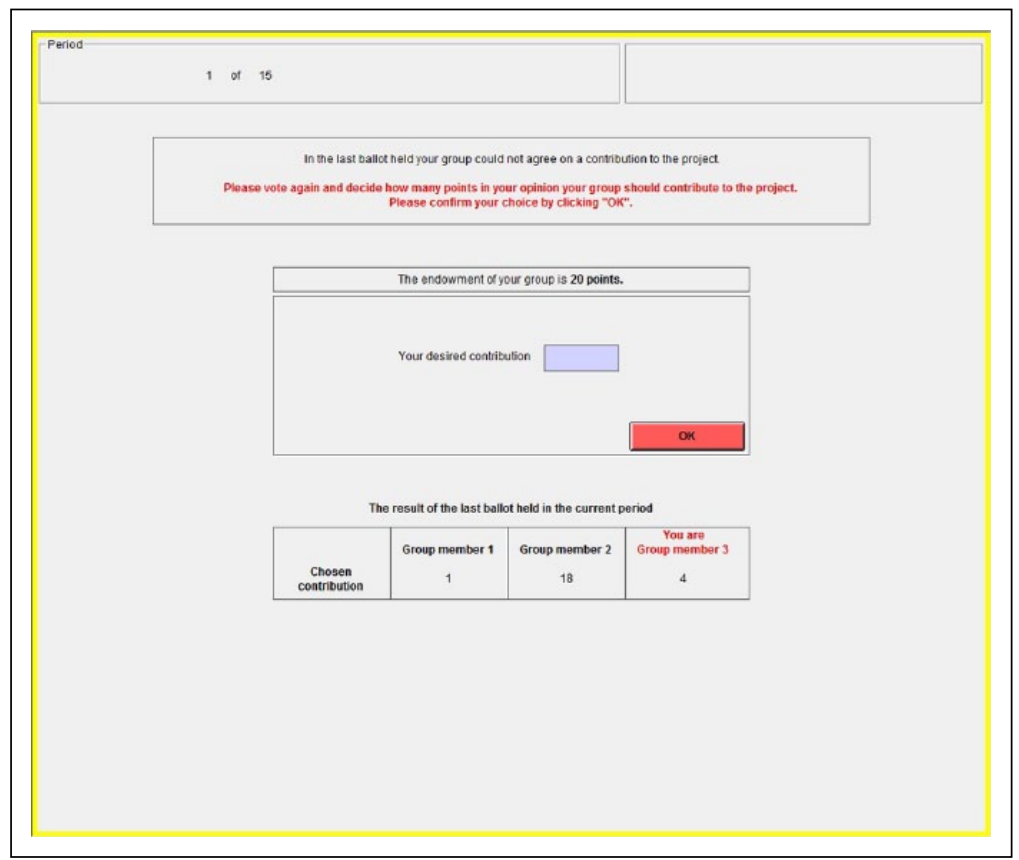

Figure 4.

If not at least two members of your group vote for an identical contribution to the project, you will be asked to vote again. Again, you can choose any number of points between 0 and 20. Please do not forget confirming your vote by clicking the "OK" button; otherwise the experiment cannot proceed.

In the table below, you can see how the other members of your group voted in the last ballot of the current period. Your column in the table is labeled with "You are" written in red letters. In the example above, you would be group member 3. In the situation depicted above, group member 1 voted for a contribution of 1 point in the last ballot of the current period, group member 2 for 18 points, and group member 3 (in this case you) for a contribution of 4 points. Accordingly, in the last ballot of the current period, no identical contribution has been chosen by at least two of the three group members. Therefore, another ballot will be held. As long as your group has not agreed on a contribution to the project, you will not get to know the contributions of the other three groups in the current period.

After repeating the ballot, the two cases as depicted above can occur again. If again no number of points receives at least two votes, you will be asked once more to cast your vote. A table shows you how you and the three 


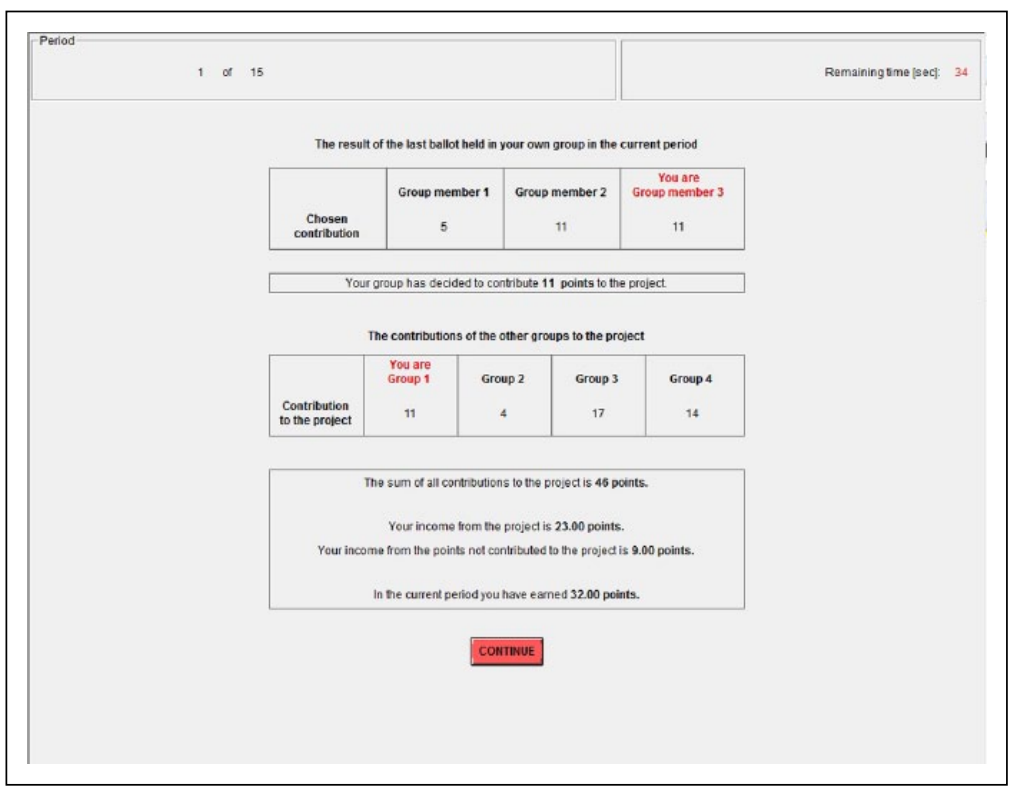

\section{Figure 5.}

other members of your group have voted in the last ballot of the current period.

Additional ballots will be held until case 2 occurs: at least two members in your group choose the same contribution.

Case 2: At least two group members of your group vote for an identical contribution of your group to the project.

If an absolute majority of at least two group members or all three group members vote for an identical number of points to contribute to the project, no new ballot will be held. In this case, your group contributes the number of points that was chosen by the majority of the group members.

When all groups have reached a decision, another screen as in Figure 5 appears. (There may be short waiting periods until the other groups have reached a decision.)

On this screen, you can see the distribution of votes of the last ballot held within your group and the resulting contribution of your group to the project (in the example above, 11 points). In an additional table, you can see how many points your group and the other groups with which your group is 
interacting have contributed to the project. In this table, the column of your group is labeled with "You are," written in red letters. In the example from above, you would be group member 3 of group 1 .

Another box is located below this table. In this box, you can find the total amount of points contributed to the project by all four groups. Below you get to know your income from the project and your income from the points that your group kept in the current period. In addition, the total amount of points you earned in this period is shown. In the first three periods, this screen will fade out automatically after 40 seconds. In the periods 4 to 15 , this screen will fade out automatically after 30 seconds. In every period, the screen will fade out earlier if you click the "CONTINUE" button.

Subsequently, a new period begins. Again, every group receives an endowment of 20 points and is asked to vote on the group's contribution to the project in the new period.

After the 15 periods, all your points earned during the experiment will be summed up. Your total payoff consists of the payoffs resulting from the points you have earned and the "show-up-fee" of $€ 2.50$.

As part of the experiment, a questionnaire will be handed to you after the last period. We ensure that the information from the questionnaire will be treated anonymously and that your data will not be revealed to any third party.

In case you have any questions, please raise your hand. We will come to your place to answer your question. 